University of Nebraska - Lincoln

DigitalCommons@University of Nebraska - Lincoln

Experimental Transmission of Chronic Wasting Disease (CWD) of Elk (Cervus elaphus nelsoni), White-tailed Deer (Odocoileus virginianus), and Mule Deer (Odocoileus hemionus hemionus) to White-tailed Deer by Intracerebral Route

A. N. Hamir

U.S. Department of Agriculture

J. A. Richt

U.S. Department of Agriculture

J. M. Miller

U.S. Department of Agriculture

R. A. Kunkle

U.S. Department of Agriculture

S. M. Hall

U.S. Department of Agriculture

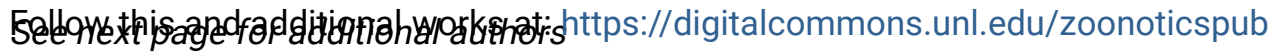

Part of the Veterinary Infectious Diseases Commons

Hamir, A. N.; Richt, J. A.; Miller, J. M.; Kunkle, R. A.; Hall, S. M.; Nicholson, E. M.; O'Rourke, Katherine I.; Greenlee, J. J.; and Williams, E. S., "Experimental Transmission of Chronic Wasting Disease (CWD) of Elk (Cervus elaphus nelsoni), White-tailed Deer (Odocoileus virginianus), and Mule Deer (Odocoileus hemionus hemionus) to White-tailed Deer by Intracerebral Route" (2008). Other Publications in Zoonotics and Wildlife Disease. 152.

https://digitalcommons.unl.edu/zoonoticspub/152

This Article is brought to you for free and open access by the Wildlife Disease and Zoonotics at DigitalCommons@University of Nebraska - Lincoln. It has been accepted for inclusion in Other Publications in Zoonotics and Wildlife Disease by an authorized administrator of DigitalCommons@University of Nebraska - Lincoln. 


\section{Authors}

A. N. Hamir, J. A. Richt, J. M. Miller, R. A. Kunkle, S. M. Hall, E. M. Nicholson, Katherine I. O'Rourke, J. J. Greenlee, and E. S. Williams 


\title{
Experimental Transmission of Chronic Wasting Disease (CWD) of Elk (Cervus elaphus nelsoni), White-tailed Deer (Odocoileus virginianus), and Mule Deer (Odocoileus hemionus hemionus) to White-tailed Deer by Intracerebral Route
}

\author{
A. N. Hamir, J. A. Richt, J. M. Miller, R. A. Kunkle, S. M. Hall, E. M. Nicholson, K. I. O’Rourke, \\ J. J. Greenlee, and E. S. Williams \\ National Animal Disease Center, ARS, USDA, Ames, IA (ANH, JAR, JMM, RAK, EMN, JJG); \\ Pathobiology Laboratory, National Veterinary Services Laboratories, Ames, IA (SMH); Animal \\ Disease Research Unit, Pullman, WA (KIO); University of Wyoming, Laramie, WY (ESW ${ }^{1}$ )
}

\begin{abstract}
To compare clinical and pathologic findings of chronic wasting disease (CWD) in a natural host, 3 groups $(n=5)$ of white-tailed deer (WTD) fawns were intracerebrally inoculated with a CWD prion of WTD, mule deer, or elk origin. Three other uninoculated fawns served as controls. Approximately 10 months postinoculation (MPI), 1 deer from each of the 3 inoculated groups was necropsied and their tissues were examined for lesions of spongiform encephalopathy (SE) and for the presence of abnormal prion protein $\left(\mathrm{PrP}^{\mathrm{d}}\right)$ by immunohistochemistry (IHC) and Western blot (WB). The remaining deer were allowed to live until they developed clinical signs of the disease which began approximately 18 MPI. By 26 MPI, all deer were euthanatized on humane grounds. Obvious differences in clinical signs or the incubation periods were not observed between the 3 groups of deer given CWD. In 1 of 3 nonclinical deer euthanatized at $10 \mathrm{MPI}$, minimal microscopic lesions of SE were seen in the central nervous system (CNS) tissues, and $\operatorname{PrP}^{\mathrm{d}}$ was observed by IHC in tissues of all 3 deer. In the clinical deer, CNS lesions of SE and $\operatorname{PrP}^{\mathrm{d}}$ accumulations were more severe and extensive. It is concluded that the 3 sources of CWD prion did not induce significant differences in time to clinical disease or qualitative differences in signs or lesions in WTD. However, this observation does not imply that these CWD agents would necessarily behave similarly in other recipient species.
\end{abstract}

Key words: Chronic wasting disease; CWD; Odocoileus virginianus; prion disease; transmissible spongiform encephalopathy; TSE; white-tailed deer.

Chronic wasting disease (CWD) is a transmissible spongiform encephalopathy (TSE) or prion disease that has been identified in captive and freeranging cervids, ${ }^{20}$ namely mule deer (Odocoileus hemionus hemionus), black-tailed deer (O. hemionus columbianus), white-tailed deer (Odocoileus virginianus), Rocky Mountain elk (Cervus elaphus nelsoni), ${ }^{14}$ and, recently, moose (Alces alces shirasi). ${ }^{1}$ Affected animals show accumulation of an abnormal, disease-associated form of prion protein $\left(\mathrm{PrP}^{\mathrm{d}}\right)$ in tissues of the central nervous system (CNS) and lymphatic system. Presence of histopathologic spongiform lesions in CNS and detection of $\mathrm{PrP}^{\mathrm{d}}$ in CNS and lymphoid tissues are the basis of currently available diagnostic methods for TSEs. $^{3}$

Experimentally, CWD has been transmitted by intracerebral inoculation of infectious material from mule deer to a variety of species, including a

1 Deceased 29 December 2004. goat, ${ }^{20}$ cattle, ${ }^{4}$ and sheep. ${ }^{5}$ CWD from white-tailed deer $\left(\mathrm{CWD}^{\mathrm{wtd}}\right)$ has also been transmitted experimentally by the intracerebral route to cattle and has shown a possible higher attack rate in cattle than $\mathrm{CWD}^{\mathrm{md}} .10$

Because it is not known whether CWD is caused by one or more different prion agents (i.e., from different species of natural hosts), the primary objective of this study was to investigate clinical and pathologic observations of CWD from 3 different sources in 1 host species: white-tailed deer (WTD) that is naturally susceptible to the disease.

\section{Materials and Methods}

\section{Animals and husbandry}

Eighteen 3-month-old WTD fawns were obtained from a CWD-free herd at the National Animal Disease Center (NADC), Ames, Iowa. The fawns were genotyped for $P R N P$ and assigned to 3 experimental groups (each $n=5$ ) and 1 control group $(n=3)$. Group No. 1 was inoculated with WTD inoculum, group No. 2 with 
Table 1. Experimental design and summary outcomes of genotype, survival period, clinical signs distribution of microscopic brain lesions and immunohistochemical labeling, and Western blots in white-tailed deer inoculated intracerebrally with the agent of Chronic Wasting Disease from elk, white-tailed deer, and mule deer.*

\begin{tabular}{|c|c|c|c|c|c|c|c|c|c|c|c|c|c|c|c|c|c|c|}
\hline \multirow[b]{2}{*}{ No. } & \multirow{2}{*}{$\begin{array}{l}\text { Ear } \\
\text { Tag } \\
\text { No. }\end{array}$} & \multicolumn{2}{|c|}{$\begin{array}{l}\text { Genotype } \\
\text { Codon }\end{array}$} & \multirow{2}{*}{$\begin{array}{l}\text { CWD } \\
\text { Inocu- } \\
\text { lation }\end{array}$} & \multirow{2}{*}{$\begin{array}{l}\text { Survival } \\
\text { Period } \\
\text { (MPI) }\end{array}$} & \multirow{2}{*}{$\begin{array}{l}\text { Clinical } \\
\text { Signs }\end{array}$} & \multicolumn{5}{|c|}{$\begin{array}{l}\text { Histopathology } \\
\text { (spongiform } \\
\text { encephalopathy) }\end{array}$} & \multicolumn{5}{|c|}{$\mathrm{IHC}$ for $\operatorname{PrP}^{\mathrm{d}}$} & \multicolumn{2}{|c|}{$\begin{array}{l}\text { Western } \\
\text { Blot BS }\end{array}$} \\
\hline & & 95 & 96 & & & & BS & Cerb & MB & Hipp & $\mathrm{RC}$ & BS & Cerb & MB & Hipp & $\mathrm{RC}$ & $2 \mathrm{~m}$ & $20 \mathrm{mg}$ \\
\hline 1 & 632 & QQ & GG & WTD & $10.36 \dagger$ & - & + & - & - & - & - & + & + & + & + & + & - & + \\
\hline 2 & 648 & QQ & GG & WTD & 17 & + & + & + & + & + & + & + & + & + & + & + & + & + \\
\hline 3 & 683 & & $\mathrm{JE}$ & WTD & 20.17 & + & NE & $\mathrm{NE}$ & NE & $\mathrm{NE}$ & $\mathrm{NE}$ & $\mathrm{NE}$ & $\mathrm{NE}$ & $\mathrm{NE}$ & NE & $\mathrm{NE}$ & NE & NE \\
\hline 4 & 628 & QQ & GS & WTD & 20.93 & + & + & + & + & - & - & + & + & + & + & + & + & + \\
\hline 5 & 654 & QQ & GS & $\begin{array}{l}\text { WTD } \\
\text { Mean }\end{array}$ & $\begin{array}{l}23.47 \\
20.4 \pm\end{array}$ & $2 \stackrel{+}{+}(\mathrm{SEM})$ & + & + & + & + & + & + & + & + & + & + & + & + \\
\hline 6 & 676 & QQ & GG & Elk & $10.37 \dagger$ & - & - & - & - & - & - & + & + & + & + & + & - & + \\
\hline 7 & 635 & QQ & GG & Elk & 17.17 & + & + & + & + & + & + & + & + & + & + & + & + & + \\
\hline 8 & 636 & QQ & GS & Elk & 17.6 & + & + & - & + & - & - & + & + & + & + & + & + & + \\
\hline 9 & 646 & QQ & GG & Elk & 17.73 & + & + & + & + & + & + & + & + & + & + & + & + & + \\
\hline 10 & 677 & QQ & GS & $\begin{array}{l}\text { Elk } \\
\text { Mean }\end{array}$ & $\begin{array}{l}24.1 \\
19.2 \pm\end{array}$ & $\stackrel{+}{+} .4(\mathrm{SEM})$ & + & + & + & + & + & + & + & + & + & + & + & + \\
\hline 11 & 684 & QQ & GS & MD & $9.33 \dagger$ & - & - & - & - & - & - & + & + & + & + & + & - & - \\
\hline 12 & 680 & QQ & GG & MD & 14.5 & + & + & + & + & + & + & + & + & + & + & + & + & + \\
\hline 13 & 639 & QQ & GG & MD & 16.1 & + & + & + & + & + & + & + & + & + & + & + & + & + \\
\hline 14 & 643 & QQ & GS & MD & 22.13 & + & + & + & + & + & + & + & + & + & + & + & + & + \\
\hline 15 & 682 & QQ & GS & $\begin{array}{l}\text { MD } \\
\text { Mean }\end{array}$ & $\begin{array}{l}26 \\
19.7 \pm\end{array}$ & $\begin{array}{c}+ \\
(\stackrel{+}{\mathrm{SEM}})\end{array}$ & + & + & + & + & + & + & + & + & + & + & + & + \\
\hline 16 & 681 & $\mathrm{QH}$ & GS & Control & 20.17 & - & - & - & - & - & - & - & - & - & - & - & - & - \\
\hline 17 & 679 & QQ & GS & Control & 26.17 & - & - & - & - & - & - & - & - & - & - & - & - & - \\
\hline 18 & 645 & QQ & GS & Control & 26.2 & - & - & - & - & - & - & - & - & - & - & - & - & - \\
\hline
\end{tabular}

$*$ MPI $=$ months postinoculation; $\mathrm{BS}=$ brainstem at obex; Cerb = cerebellum; $\mathrm{MB}=$ midbrain at the level of superior colliculi; Hipp = hippocampus; RC = rostral cerebrum; IHC = immunohistochemistry; WTD = white-tailed deer; MD = mule deer; $\mathrm{NE}=$ tissues not available for examination

$\dagger$ Euthanatized at 9-10 MPI (not included in the mean).

elk inoculum, and group No. 3 with mule deer inoculum, and control group No. 4 was uninoculated (Table 1). All CWD-inoculated deer were homozygous at $P R N P$ gene polymorphic amino acid sites at codon 95 (glutamine) and 116 (serine). Deer homozygous (glycine/ glycine) or heterozygous (glycine/serine) at codon 96 were approximately equally divided between treatment groups (Table 1). Inoculated fawns were housed in a Biosafety Level 2 isolation barn at NADC; the husbandry of TSE-inoculated animals has been described previously. ${ }^{12}$ Personnel wore protective clothing while in the isolation facility and showered before leaving the facility.

\section{Inoculum}

The CWD ${ }^{\text {wtd }}$ inoculum was prepared from a pool of 11 CWD-affected WTD brainstems from Wisconsin; the CWD inoculum from elk $\left(\mathrm{CWD}^{\mathrm{elk}}\right)$ was a pool of 2 CWD-positive elk brainstems from South Dakota, and the CWD ${ }^{\text {md }}$ inoculum was a pool of 28 CWD-affected mule deer brains from Wyoming. In all 3 instances, the animals from which the inocula were prepared were positive by immunohistochemistry (IHC) for $\operatorname{PrP}^{\mathrm{d}}$. The affected brain tissues were ground in a mechanical grinder, and gentamicin was added to attain a final concentration of $100 \mu \mathrm{g} / \mathrm{ml}$ in the homogenized inoculum. The final concentration of the brain inoculum was $10 \%(\mathrm{wt} / \mathrm{vol})$ in phosphate-buffered saline (PBS). The pooled samples of all 3 inocula were positive for CWD prion protein by Western blot (WB). In addition, CWD inocula from mule deer and WTD were previously reported effective in producing prion disease in cattle when administered by the intracerebral route. ${ }^{4,10}$

\section{Inoculation procedure}

The deer were inoculated intracerebrally with $1 \mathrm{ml}$ of either $\mathrm{CWD}^{\mathrm{wtd}}, \mathrm{CWD}^{\mathrm{elk}}$, or $\mathrm{CWD}^{\mathrm{md}}$ inocula as described previously for sheep. ${ }^{11}$ Briefly, the fawns were sedated with xylazine, a midline incision was made in the skin at the junction of the parietal and frontal bones, and a $1-\mathrm{mm}$ hole was trephined through the calvarium. The inoculum was injected into the midbrain via a 22gauge 9-cm-long needle while withdrawing the needle from the brain. The skin incision was closed with a single suture.

\section{Necropsy, tissue samples}

Except for the 3 animals killed at about 10 MPI (Nos. 632, 676, 684; Table 1), all others were euthana- 
tized when in extremis. One control animal (No. 681; Table 1) was euthanatized earlier, and the other 2 controls were euthanatized at the termination of the experiment (Nos. 679, 645; Table 1). Animals were euthanatized with pentobarbital sodium overdose, and a complete necropsy was conducted on each of the carcasses. One deer (No. 683; Table 1) was not available for necropsy. Representative samples of liver, kidney, spleen, skin, striated muscles (heart, tongue, diaphragm, masseter), thoracic aorta, thyroid gland, turbinates, trachea, lung, tonsils, esophagus, rumen, reticulum, omasum, abomasum, intestine (ileum), salivary gland, adrenal gland, urinary bladder, lymph nodes (retropharyngeal, prescapular, mesenteric, popliteal), nerves (optic, trigeminal), pituitary gland, Gasserian ganglion, and spinal cord (cervical, thoracic, lumbar) were fixed by immersion in 10\% neutral buffered formalin. One eye was fixed in Bouin's solution. The brain was bisected longitudinally; one half was fixed in formalin for not less than 3 weeks and the other half was frozen. The formalin-fixed brain was cut into 2-4-mm-thick coronal sections. A minimum of 5 hemisections of brain per animal-rostral cerebrum, hippocampus, superior colliculus, cerebellum, brainstem (at the level of obex) and 6 sections of spinal cord (2 each of cervical, thoracic, and lumbar) were processed by routine histology procedures, embedded in paraffin wax, and sectioned at $5 \mu \mathrm{m}$ thickness.

The sections were stained with hematoxylin and eosin (HE). Selected sections of the brain were also stained by periodic acid-Schiff (PAS), Gomori's methenamine silver (GMS), and Congo Red stains. The latter sections were examined under polarized light to detect presence of amyloid.

\section{Immunohistochemistry}

All paraffin-embedded tissues were also stained by an automated IHC method for detection of $\mathrm{PrP}^{\mathrm{d}}$ as described previously. ${ }^{8}$ Monoclonal antibody (Mab), F99/ 97.6. $1^{16}$ was used for the IHC at a final concentration of $1.0 \mu \mathrm{g} / \mathrm{ml}$ protein. Past experience at NADC has indicated this antibody would recognize $\operatorname{PrP}$ sequences in various species. ${ }^{2,4-6,9,10} \mathrm{CNS}$ tissues of 1 positive animal (No. 3661) were also labeled by IHC with Mab $6 \mathrm{H} 4(0.2 \mu \mathrm{g} / \mathrm{ml})$.

\section{Western blot analyses}

Brainstem homogenates from WTD were analyzed using the Prionics ${ }^{\circledR}$-Check Western Kit (Prionics, Schlieren, Switzerland) and the OIE-recommended Scrapie Associated Fibril (SAF)-Immunoblot method ${ }^{14}$ with minor modifications as previously described. ${ }^{19}$

\section{PRNP genotyping: DNA isolation and polymerase chain reaction amplification}

Genomic DNA was extracted from $200 \mu \mathrm{l}$ of a $10 \%$ brain homogenate with the DNeasy ${ }^{\mathrm{TM}}$ tissue kit (Qiagen, Valencia, CA) according to the manufacturer's instructions. Polymerase chain reaction was performed in a $100-\mu$ final reaction volume as previously described. ${ }^{19}$

\section{Statistical analysis}

Incubation periods of the 3 treatment groups were compared with the 2-sided Student's $t$-test. Probability values of $P<.05$ were considered to indicate a statistically significant difference between groups.

\section{Results}

Three WTD euthanatized at approximately 10 MPI did not show clinical signs of CWD (Table 1). The remainder of the CWD-inoculated deer revealed characteristic signs of the disease, and all were euthanatized between 18 and 26 MPI. The clinical signs included gradual decrease in appetite with consequent weight loss. During the latter part of the disease (which varied from a few days to a week) the animals had difficulty in swallowing and were seen to regurgitate feed intermittently. There was also excessive salivation. In the terminal phase of the disease, the affected deer appeared to be unaware of their surroundings; had lost fear of humans; occasionally showed disorientation, bruxism, and intermittent circling to one side; and eventually became recumbent. They were euthanatized when in extremis. Clinical signs in animals in all 3 treatment groups were similar. Although the survival times of individual deer varied from 14.5 to $26 \mathrm{MPI}$, mean survival times did not differ significantly among groups $(P \geq .5$; Table 1$)$.

Except for the loss of body condition, significant gross lesions were not seen in any of the experimental deer. No lesions were present in the 3 control deer.

Although the 3 deer euthanatized at 10 MPI did not have clinical signs, there were minimal microscopic lesions of spongiform encephalopathy (SE) in the brainstem of deer No. 632 (Fig. 1; Table 1). However, $\operatorname{PrP}^{\mathrm{d}}$ was observed by IHC in CNS (Fig. 2) and lymphoid tissues of all 3 animals without clinical signs (Table 1).

Lesions in the CNS were more severe and extensive in deer with clinical signs (Table 1, Figs. 3-6) than in deer without clinical signs (Table 1, No. 632) euthanatized at 10 MPI. Severe multifocal spongiform lesions consisting of vacuolation of neuropil and an occasional vacuole within neuronal perikarya were seen in the brains and spinal cords of all affected deer (Figs. 3-6). Mild multifocal gliosis was seen at the affected sites, but neuronal degeneration was not seen. Additionally, in the rostral cerebral cortex of all deer with clinical signs were variable numbers of randomly distributed plaques that contained eosinophilic fine 

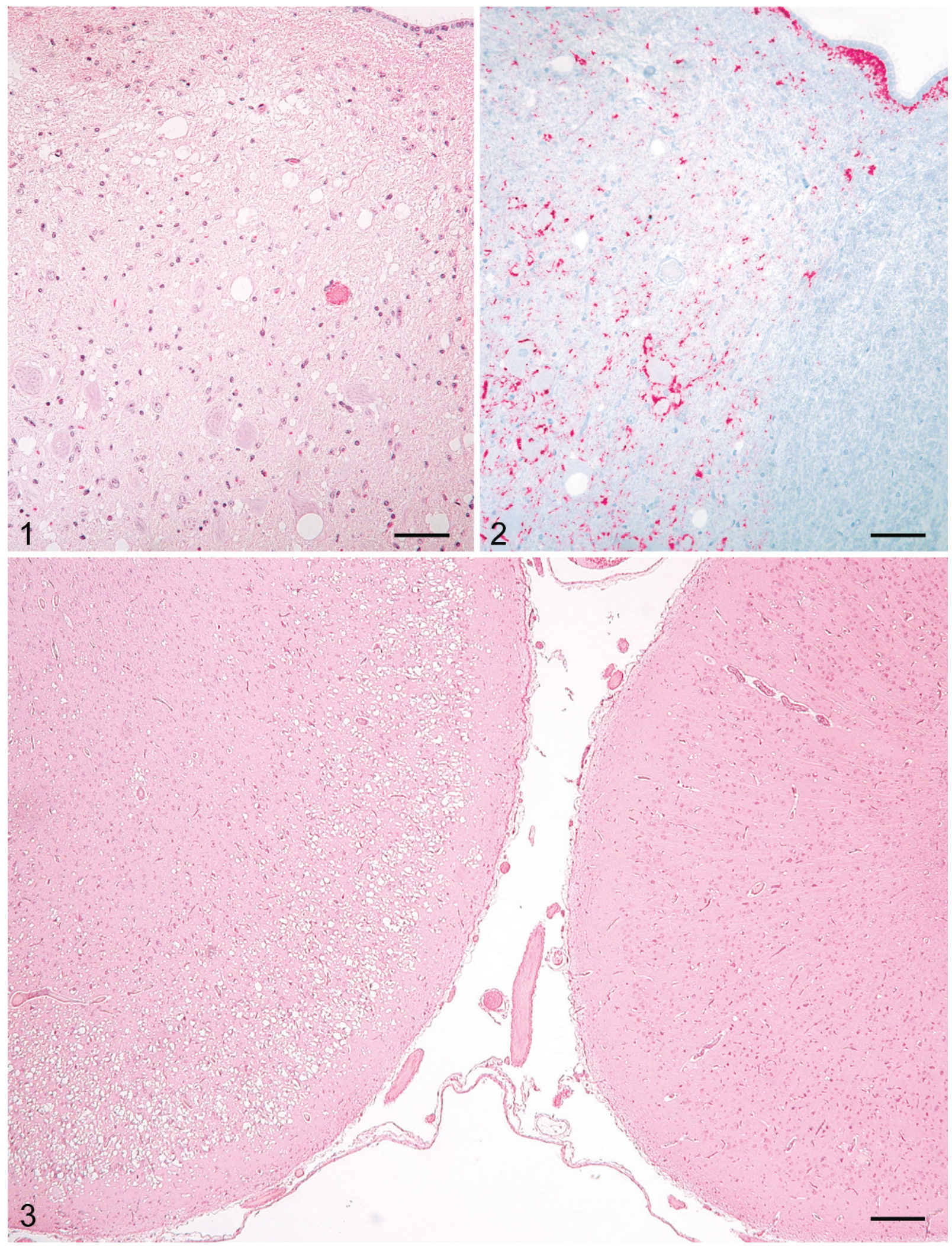

Fig. 1. Brain, brainstem (obex), dorsal vagal nucleus; nonclinical deer No. 632 (03-1267). Moderate spongiform encephalopathy. HE. Bar $=60 \mu \mathrm{m}$. 

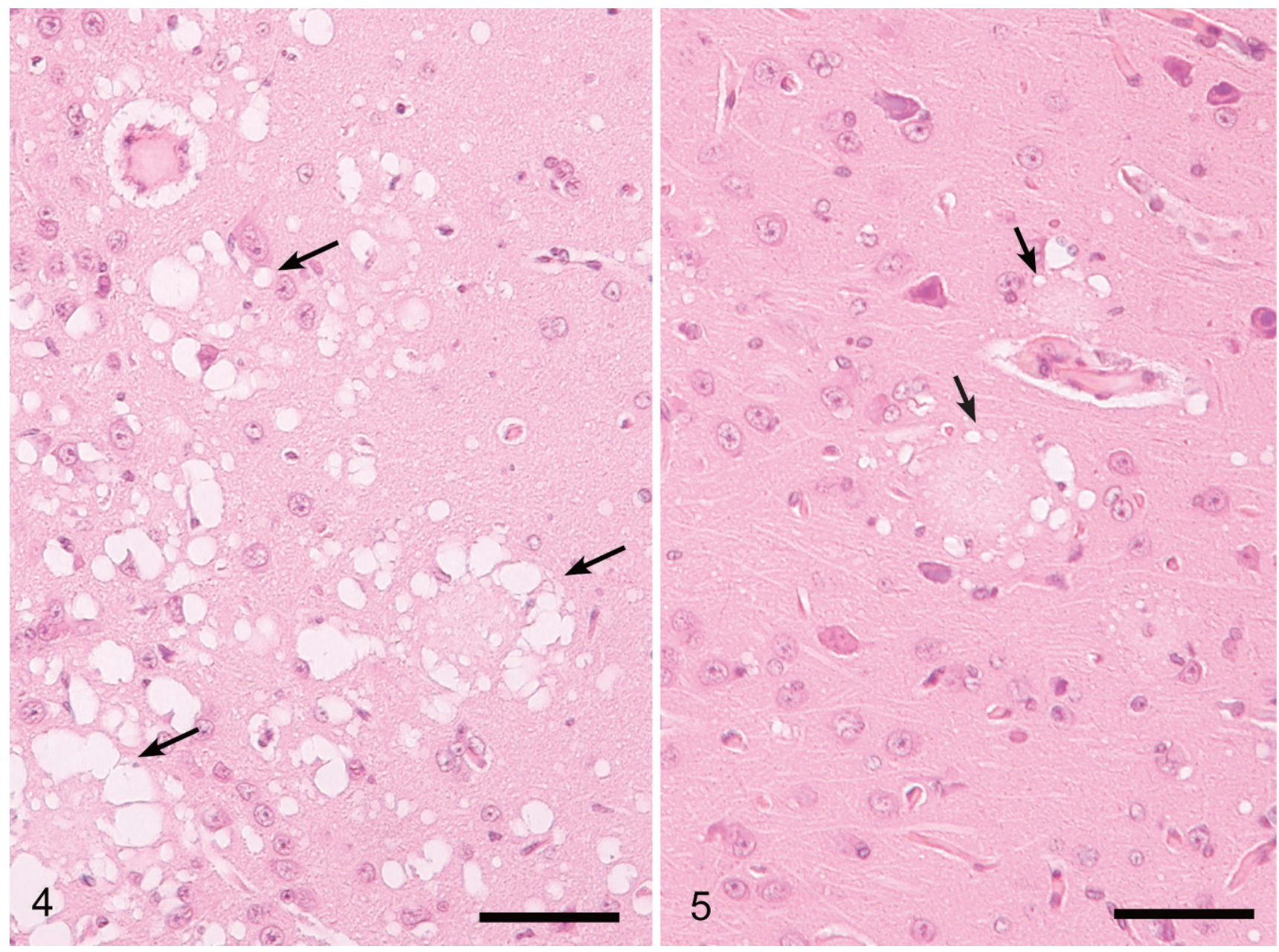

Fig. 4. Brain, rostral cerebral cortex; clinical deer No. 648. Higher magnification of gyrus with spongiform encephalopathy in Fig. 5 showing several florid plaques (arrows). HE. Bar $=60 \mu \mathrm{m}$.

Fig. 5. Brain, rostral cerebral cortex; clinical deer No. 648. Higher magnification of gyrus with minimal changes in Fig. 6 showing 2 florid plaques with a few surrounding clear vacuoles (arrows). HE. Bar $=60 \mu \mathrm{m}$.

fibrillar material (Figs. 4, 5). These plaques were present both within the areas of SE (Fig. 4) as well as some distance from these lesions (Fig. 5). Plaques in the areas of SE were surrounded by many clear vacuoles (florid plaques; Fig. 4), whereas in the unaffected areas, a few small peripheral vacuoles surrounded the plaques (Fig. 5). Many of the plaques revealed centrally located fibrillar GMS- and PAS-positive material (Fig. 6). Both stains enabled easy detection of florid plaques within a section. When examined under polarized light, the amyloid red-stained sections revealed faint apple-green material (amyloid) within some of the plaques.

The location of SE in the brains is summarized in Table 1. In the brainstem, the lesions were more severe and diffuse and although they were present in all nuclei, they appeared to be more extensive in the dorsal nucleus of the vagus. Lesions in the hippocampus were moderate and multifocal. Sections of the colliculi revealed mild diffuse vacuolation in the neuropil. In the rostral cerebrum,

Fig. 2. Brain, brainstem (obex), dorsal vagal nucleus; nonclinical deer No. 632. Particulate labeling is scattered in the neuropil and around neurons and blood vessels. Also, there is some $\operatorname{PrP}^{\mathrm{d}}$ labeling in the subependymal area. Labeled for $\operatorname{PrP}^{\mathrm{d}}$ by IHC. Bar $=60 \mu \mathrm{m}$.

Fig. 3. Brain, rostral cerebral cortex; clinical deer No. 648. In two adjacent gyri, the left gyrus has extensive diffuse spongiform encephalopathy, whereas the right has minimal changes. HE. Bar $=160 \mu \mathrm{m}$. 

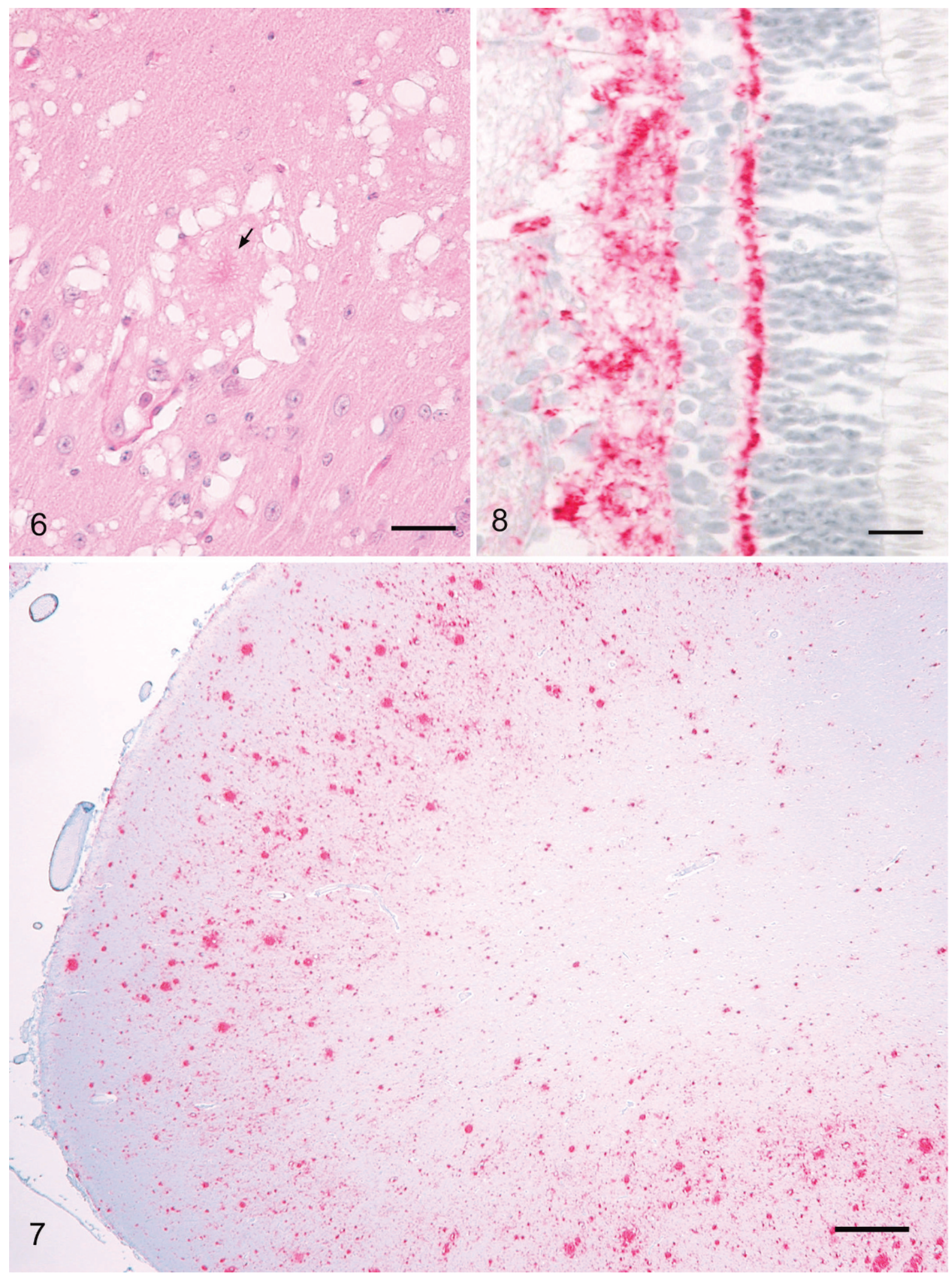

Fig. 6. Brain, rostral cerebral cortex; clinical deer No. 648. Higher magnification showing a florid plaque with central fibrillar PAS-positive material. PAS. Bar $=60 \mu \mathrm{m}$.

Fig. 7. Brain, rostral cerebral cortex; clinical deer No. 648. There is diffuse granular $\operatorname{PrP}^{\mathrm{d}}$ labeling of cortical gray matter. Within this area are many intensively labeled florid plaques. Labeled for $\operatorname{PrP}^{\mathrm{d}}$ by IHC. Bar $=70 \mu \mathrm{m}$.

Fig. 8. Eye, retina; clinical deer No. 648. There is diffuse granular labeling of $\operatorname{PrP}^{\mathrm{d}}$ in the inner and outer plexiform layers. The ganglion cell layer shows fine multifocal labeling. Labeled for $\operatorname{PrP}^{\mathrm{d}}$ by IHC. Bar $=40 \mu \mathrm{m}$. 
lesions were confined to the cortex and consisted of extensive multifocal to coalescing areas of SE (Figs. 3-6). Often a severely affected gyrus would be adjacent to a nonaffected or minimally affected gyrus (Fig. 3). The cerebellum also had mild to moderate multifocal areas of vacuolations in the cerebellar folia involving predominantly the molecular and Purkinje cell layers.

A focal pulmonary abscess in 1 deer (No. 635) suggested focal aspiration pneumonia. Other incidental findings included ectopic lymphoid follicles in the medulla of 1 kidney in deer No. 632, focal mineralization of the blood vessels in the brains of 3 deer (Nos. 628, 680, 681), and sarcocysts in skeletal muscles of 5 deer. No other significant lesions were seen in the tissues of experimental or control deer.

Although microscopic lesions were not evident in all brain sections, $\operatorname{PrP}^{\mathrm{d}}$ was detected by IHC in all (Table 1). Immunolabeling by IHC was more abundant in the CNS but roughly equivalent in lymphoid tissues of the clinical deer compared with the nonclinical deer that were euthanatized at approximately $10 \mathrm{MPI}$. Differences in IHC findings between groups (i.e., treatment groups by CWD inocula source or codon 96 polymorphism genotype) were not noted. Negative control deer sacrificed at 26 months postinoculation did not have immunolabeling for $\operatorname{PrP}^{\mathrm{d}}$.

The $\operatorname{PrP}^{\mathrm{d}}$ labeling in the CNS of deer without clinical signs was predominantly characterized by well-delineated and abundant accumulations in subependymal neuropil in both brain and spinal cord sections. The $\mathrm{PrP}^{\mathrm{d}}$ distribution in the CNS of clinically affected deer was multifocally extensive to diffuse and was perineuronal, subependymal, and neuropil associated (Fig. 2). $\operatorname{PrP}^{\mathrm{d}}$ labeling was pronounced in the midbrain but relatively sparse in the hippocampus. Spinal cord sections revealed $\operatorname{PrP}^{\mathrm{d}}$ accumulations predominately in the gray matter horns. Intensely labeled plaques, with and without peripheral neuropil vacuolation (florid plaques), was a prominent feature in the deer with advanced CWD (Fig. 7). Intraneuronal labeling in the CNS was not observed.

$\operatorname{PrP}^{\mathrm{d}}$ was consistently detected by IHC in lymph nodes, mainly in germinal centers of cortical follicles. $\operatorname{PrP}^{\mathrm{d}}$ was detected by IHC in splenic periarteriolar sheaths in only 5 of 13 deer, with no clear pattern of splenic labeling by IHC in relation to stage of disease or PrP genotype. Only 3 of 13 third eyelid specimens examined contained submucosal lymphoid tissue, and $\mathrm{PrP}^{\mathrm{d}}$ labeling was seen in only 1 deer (No. 677). Submucosal lymphoid tissue in the ileum (Peyer's patches) was consistently labeled for
$\operatorname{PrP}^{\mathrm{d}}$, as were ganglia in the myenteric plexus. Unlike labeling seen in the CNS, $\operatorname{PrP}^{\mathrm{d}}$ accumulations were localized to the perikaryon as well as to perineuronal foci in the myenteric plexus.

Gasserian ganglia were uniformly devoid of $\operatorname{PrP}^{\mathrm{d}}$. However, light to moderate punctuate labeling was present in trigeminal nerve tissue obtained from several clinically affected deer. Retinal tissue contained abundant $\operatorname{PrP}^{\mathrm{d}}$ in all clinically affected deer, but not in deer euthanatized at 10 MPI. The IHC labeling localized predominately to the plexiform layers of the retina, with lesser amounts present in the ganglion cell layer (Fig. 8) and optic nerve of some deer.

When WB analysis with 2-mg brain equivalent (eq) amounts was performed, all samples except Nos. 632, 676, 684, 681, 679, and 645 showed a pattern with the presence of all 3 isoforms of the protease-resistant $\mathrm{PrP}^{\mathrm{d}}$ (Fig. 9). To determine whether higher milligram equivalent amounts of brainstem would show a different reaction pattern, brainstems of Nos. 632, 676, and 684 were analyzed at $20-\mathrm{mg}$ brain eq. At this concentration, sample Nos. 632 and 676 were positive for $\operatorname{PrP}^{\mathrm{d}}$ (Fig. 10). Sample No. 684 was negative at $20 \mathrm{mg}$ eq (Fig. 10), as well as at $100 \mathrm{mg}$ eq (data not shown).

When representative samples from WTD inoculated either with $\mathrm{CWD}^{\mathrm{wtd}}, \mathrm{CWD}^{\mathrm{md}}$, or $\mathrm{CWD}^{\mathrm{elk}}$ were compared side by side, no difference in the molecular mass of the 3 protease-resistant isoforms (unglycosylated, monoglycosylated, diglycosylated) of the $\operatorname{PrP}^{\mathrm{d}}$ was noted (Fig. 9). The molecular pattern was not different when $\operatorname{PrP}^{\mathrm{d}}$-positive deer were compared with different PrP genotypes (e.g., GG96 versus GS96) (Fig. 9).

Analysis of the open reading frame of the $P R N P$ from codon 11 through codon 235 revealed polymorphic sites on codons 95 and 96 (Table 1). One animal, No. 681, was heterozygous for glutamine/histidine $(\mathrm{Q} / \mathrm{H}$; CAA/CAC) at codon 95; all other animals were homozygous for glutamine $(\mathrm{Q} /$ Q; CAA/CAA) at that position. Codon 96 can code for either glycine $(G=G G T)$ or serine $(S=A G T)$. Seven animals were homozygous (G/G) and 10 animals were heterozygous $(\mathrm{G} / \mathrm{S})$ at this position. All animals were homozygous for alanine (A/A) at codon 116 and for serine (S/S) at codon 138. No unknown polymorphisms were found in the $P R N P$ of these animals, and the $P R N P$ gene of all animals encoded 5 octa/nonapeptide repeat units. ${ }^{19}$ Silent changes were identified in some animals: GAC/ GAT at codon 20 (Nos. 628, 635, 681), CGT/CGC at codon 51 (No. 628), AAC/AAT at codon 146 (No. 676), and ATC/ATT at codon 185 (Nos. 628, $636,639,645,676,679,681,682)$. 


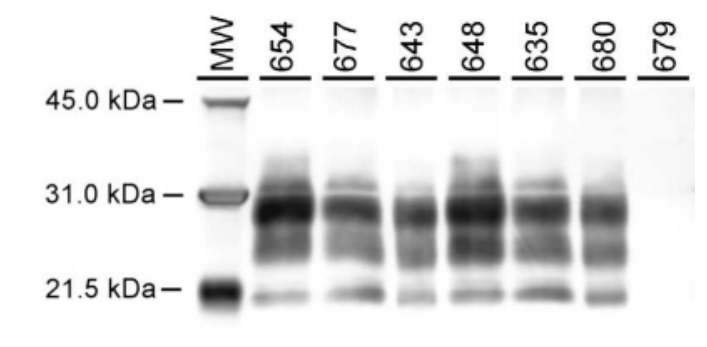

9

\section{0}

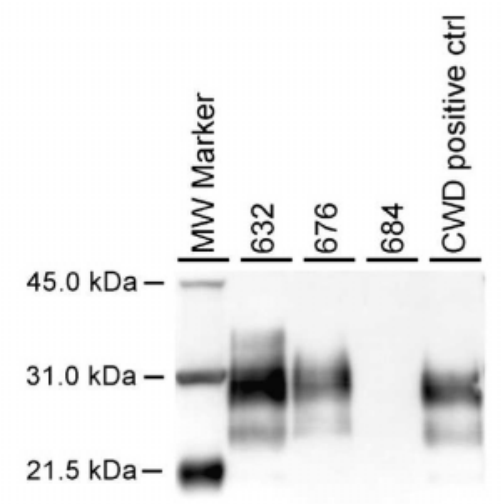

Fig. 9. Western blot analysis of representative brainstem samples from white-tailed deer inoculated with CWD $^{\text {wtd }}$ (Nos. 654 and 648), CWD ${ }^{\text {md }}$ (Nos. 643 and 680), and CWD $^{\text {elk }}$ (Nos. 677 and 635). Deer No. 679 represents a negative control animal. Samples were probed with monoclonal antibody $6 \mathrm{H} 4$ and loaded at $0.1-0.3 \mathrm{mg}$ brain eq per lane. Positive samples show distinct protease-resistant profiles of $\operatorname{PrP}^{\mathrm{d}}$. Different $\operatorname{PrP}$ genotypes were loaded: GS96 (Nos. 654, 677, 643) and GG96 (Nos. 648, 635, 680). Molecular weight markers $(\mathrm{kDa})$ are indicated on the left side of the blot.

Fig. 10. Western blot analysis with monoclonal antibody $6 \mathrm{H} 4$ after $\mathrm{PrP}^{\mathrm{d}}$ enrichment of brainstem. Sample Nos. 632, 676, and 684 were loaded at $20 \mathrm{mg}$ brain eq. The positive control sample was loaded at $1 \mathrm{mg}$ brain eq. Molecular weight markers (kDa) are indicated on the left side of the blot.

\section{Discussion}

In this study, we used the intracerebral route of inoculation to provide the most efficient means of testing the susceptibility of WTD to the 3 agents of CWD (from WTD, elk, and mule deer). In WTD, polymorphism at codons $95,96,116$, and 138 of the PRNP gene has been reported. ${ }^{17}$ However, in this study, although there was no uniformity at codon 96 , it did not appear to have had any influence on the outcome of disease.

Like all other TSEs, CWD is characterized by a long incubation period, which in deer is seldom less than 18 months. ${ }^{20}$ In our study, the mean survival time was just over 19 MPI and was not significantly different in the groups given 3 different CWD isolates (Table 1). Previous studies have found differences in attack rates in cattle ${ }^{4,10}$ after inoculation of $\mathrm{CWD}^{\mathrm{md}}$ and $\mathrm{CWD}^{\mathrm{wtd}}$, and similar findings might also be true for fallow deer. ${ }^{7}$ Therefore, the indication is that more than 1 strain of CWD could be present, and such a hypothesis appears to be supported by other work. ${ }^{13,18}$ However, in this study, no such differences were identified, suggesting that WTD are not appropriate challenge hosts for differentiating strains of CWD, although the study is compromised because the infectious dose was not determined and limiting doses were not used.

In all cervids, clinical signs of CWD are characterized by emaciation, changes in behavior, and excessive salivation. ${ }^{20}$ In this study, both excessive salivation and behavioral changes were observed in animals that had clinical signs. Also, weight loss was considerable, but frank emaciation was not observed in any of the clinical deer, possibly because the animals in the study were in a controlled environment and were never far from the familiar source of feed and water, which would have helped in maintaining some body condition.

In the 3 WTD that were euthanatized at approximately $10 \mathrm{MPI}$, there were no clinical signs of CWD. However, on microscopic examinations, one of the deer had microscopic lesions of SE in the brain stem, and all 3 showed presence of $\operatorname{PrP}^{\mathrm{d}}$ in their brains by IHC and 2 out of 3 by WB. Although in these animals the inoculum was administered by the intracerebral route, by 10 MPI, the lymphoid tissues of all 3 deer were positive also for $\mathrm{PrP}^{\mathrm{d}}$ by IHC. Because of recent evidence of presence of $\operatorname{PrP}^{\mathrm{d}}$ in blood and saliva of CWD-infected deer, ${ }^{15}$ it is possible that during or soon after the inoculation procedure, some of the inoculum could have gained access to the circulatory system and hence been transported to the lymph nodes.

In these deer, the observed neuronal lesions of SE have been described previously. ${ }^{20}$ Microscopically, the most impressive lesion was the extensive $\mathrm{SE}$ with presence of numerous plaques in the rostral cerebral cortex. These are most frequently seen in WTD, followed by mule deer and elk with CWD. ${ }^{20}$

The distribution and character of $\operatorname{PrP}^{\mathrm{d}}$ labeling by IHC in the WTD tissues was not apparently influenced by the source of CWD inoculum or by the genotype of the PRNP for GG96 compared with GS96. Labeling was intense and well distrib- 
uted in lymphoid tissues in nonclinical as well as CWD-affected deer, whereas $\operatorname{PrP}^{\mathrm{d}}$ accretion in the CNS was apparently dependent on incubation period. The early accumulation of $\mathrm{PrP}^{\mathrm{d}}$ in predominately subependymal foci could be a consequence of the intracerebral inoculation method, which targets the midbrain, including the cerebral aqueduct, as the initial point of inoculum deposition. The increased labeling of $\mathrm{PrP}^{\mathrm{d}}$ in the CNS of CWD-affected deer was exemplified by the uniform presence of $\operatorname{PrP}^{\mathrm{d}}$ in retinal tissues in all but the nonclinical deer sacrificed at 10 MPI.

The lack of intraneuronal labeling in the CNS and total absence in the Gasserian ganglia juxtaposed to the labeling of perikaryon in myenteric plexus neurons is an interesting and puzzling finding. The spleen and third eyelid were poor candidate tissues for IHC immunodiagnosis in this study. The paucity of nictitating membrane submucosal lymphoid tissue in these deer could be a reflection of the relatively clean, dust-free environment afforded by biocontainment housing and consequent lack of antigenic stimulation to this mucosal surface.

When 2-mg brain eq amounts were analyzed by WB, all animals euthanatized with clinical signs of CWD were positive for $\operatorname{PrP}^{\mathrm{d}}$. The 3 animals euthanatized without clinical signs at about 10 MPI were either questionable or negative for the presence of $\operatorname{PrP}^{\mathrm{d}}$. We therefore enriched $\mathrm{PrP}^{\mathrm{d}}$ using a modified OIE-recommended WB technique. ${ }^{14}$ When $20 \mathrm{mg}$ eq were loaded, 2 out of these 3 animals were WB positive (Fig. 10). The negative animal, No. 684, was further tested at $100 \mathrm{mg}$ eq and still gave no positive signal for $\operatorname{PrP}^{\mathrm{d}}$. This indicates that the WB method at early time points (MPI) when few cells are $\mathrm{PrP}^{\mathrm{d}}$ positive is not as sensitive as the IHC method, which determined animal No. 684 positive for $\operatorname{PrP}^{\mathrm{d}}$ (Table 1). Because one half of the brain was formalin-fixed and analyzed by IHC and the other half was frozen and used for WB analysis, it was also possible that the WB sample did not contain $\operatorname{PrP}^{\mathrm{d}}$.

No significant differences in the molecular profile were observed in WTD inoculated with 3 different CWD inocula $\left(\mathrm{CWD}^{\mathrm{wtd}}, \mathrm{CWD}^{\mathrm{md}}\right.$, $\mathrm{CWD}^{\mathrm{elk}}$; Fig. 9). This was also true when different PrP genotypes of WTD (GS96, GG96) were compared. This indicates that CWD from different sources inoculated into WTD results in similar molecular phenotypes independent of the origin of the inoculum. It was shown previously ${ }^{17}$ that captive deer affected with CWD are less likely to have the $\mathrm{Q}_{95} \mathrm{~S}_{96} \mathrm{~A}_{118} \mathrm{~S}_{138}$ genotype and more likely to have the $\mathrm{Q}_{95} \mathrm{G}_{96} \mathrm{~A}_{118} \mathrm{~S}_{138}$ genotype. Likewise, it was suggested that GS96 was linked to reduced susceptibility to CWD and slower progression of disease in WTD. ${ }^{12}$

With intracerebal inoculation of CWD, there was a trend toward a longer incubation time for deer carrying the GS96 heterozygous (mean 22.4 months) compared with GG96 homozygous genotype (mean 16.5 months) (see Table 1). Although only a small number of animals were enrolled in this study, the effect of codon GS96 polymorphism on incubation time was significant $(P<.01)$. Interestingly, the GS96 heterozygous animal No. 684 was negative in WB even at $100 \mathrm{mg}$ brain eq, indicating a slower progression of $\mathrm{PrP}^{\mathrm{d}}$ accumulation when compared with the other 2 animals representing the GG96 genotype sacrificed at a similar time point postinoculation.

This study did not demonstrate obvious differences in the clinical or pathologic outcome of infection with prion among the 3 CWD inocula that were used to produce disease in WTD. However, PRNP gene polymorphism at codon 96 in the recipient deer revealed differences in survival times. Since the $2 \mathrm{CWD}$ inocula $\left(\mathrm{CWD}^{\mathrm{wtd}}\right.$ and $\mathrm{CWD}^{\mathrm{md}}$ ) in cattle ${ }^{4,10}$ revealed significant differences in attack rates, further studies are indicated to investigate the potential role of other CWD prions derived from different cervids, including moose.

\section{Acknowledgements}

We thank Dr. Mitch Palmer for providing the fawns; Drs. L. Nusz and J. Laufer for clinical assistance; Dr. Marcus Kehrli Jr. for statistical analysis, constructive comments, and his enthusiastic support; and James Fosse for the photomicrographs. Expert technical assistance was provided by Martha Church, Dennis Orcutt, Joseph Lesan, Trudy Tatum, Deb Clouser, Kevin Hassall, Ginny Montgomery, Micky Fenneman, and the TSE animal caretakers.

This study was carried out under the guidelines of the institutional ACUC committee at NADC. Mention of trade names or commercial products in this article is solely for the purpose of providing specific information and does not imply recommendation or endorsement by the US Department of Agriculture.

\section{References}

1 Baeten LA, Powers BE, Jewell JE, Spraker TR, Miller MW: A natural case of chronic wasting disease in a free-ranging moose (Alces alces shirasi). J Wildl Dis 43:309-314, 2007

2 Cutlip RC, Miller JM, Race RE, Jenny AL, Katz JB, Lehmkuhl HD, DeBey BM, Robinson MM: Intracerebral transmission of scrapie to cattle. J Infec Dis 169:814-820, 1994 
3 Gavier-Widen D, Stack MJ, Baron T, Balachandran A, Simmons M: Diagnosis of transmissible spongiform encephalopathies in animals: a review. J Vet Diagn Invest 17:509-527, 2005

4 Hamir AN, Kunkle RA, Cutlip RC, Miller JM, O'Rourke KI, Williams ES, Miller MW, Stack MJ, Chaplin MJ, Richt JA: Experimental transmission of chronic wasting disease agent to cattle by the intracerebral route. J Vet Diagn Invest 17:276-281, 2005

5 Hamir AN, Kunkle RA, Cutlip RC, Miller JM, Williams ES, Richt JA: Transmission of chronic wasting disease agent of mule deer $\left(\mathrm{CWD}^{\mathrm{md}}\right)$ to Suffolk sheep by intracerebral route. J Vet Diagn Invest 18:558-565, 2006

6 Hamir AN, Kunkle RA, Miller JM, Bartz JC, Richt JA: First and second cattle passage of transmissible mink encephalopathy (TME) by intracerebral inoculation. Vet Pathol 43:118-126, 2006

7 Hamir AN, Kunkle RA, Nicholson EM, Miller JM, Hall SM, Schoenenbruecher H, Richt JA: Preliminary observations on the experimental transmission of chronic wasting disease (CWD) from elk and white-tailed deer to fallow deer. J Comp Pathol 138:121-130, 2008

8 Hamir AN, Kunkle RA, Richt JA, Miller JM, Greenlee JJ: Experimental transmission of US scrapie agent by nasal, peritoneal and conjunctival routes to genetically susceptible sheep. Vet Pathol 45:7-11, 2008

9 Hamir AN, Miller JM, Cutlip RC, Kunkle RA, Jenny AL, Stack MJ, Chaplin MJ, Richt JA: Transmission of sheep scrapie to elk (Cervus elaphus nelsoni) by intracerebral inoculation: final outcome of the experiment. J Vet Diagn Invest 16:316-321, 2004

10 Hamir AN, Miller JM, Kunkle RA, Hall SM, Richt JA: Susceptibility of cattle to first-passage intracerebral inoculation with chronic wasting disease agent from white-tailed deer. Vet Pathol 44:487-493, 2007

11 Hamir AN, Miller JM, Stack MJ, Chaplin MJ: Failure to detect abnormal prion protein and scrapie-associated fibrils $6 \mathrm{wk}$ after intracerebral inoculation of genetically susceptible sheep with scrapie agent. Can J Vet Res 66:289-294, 2002

12 Johnson C, Johnson J, Vanderloo JP, Keane D, Aiken JM, McKenzie D: Prion protein polymor- phisms in white-tailed deer influence susceptibility to chronic wasting disease. J Gen Virol 87:2109-2114, 2006

13 LaFauci G, Carp RI, Meeker HC, Ye X, Kim JI, Natelli M, Cedeno M, Petersen RB, Kascsak R, Rubenstein R: Passage of chronic wasting disease prion into transgenic mice expressing Rocky Mountain elk (Cervus elaphus nelsoni) PrP ${ }^{\mathrm{c}}$. J Gen Virol 87:3773-3780, 2006

14 Mathews D, Jeffery M, Simmons MM, Stack M, Wells GAH, Wilesmith JW: Bovine spongiform encephalopathy. In: OIE Manual of Diagnostic Tests and Vaccines for Terrestrial Animals, chap. 2.3.13, World Organisation for Animal Health, www. oie.int/eng/normes/mmanual/A_summry.htm, 2004

15 Mathiason CK, Powers JG, Dahmes SJ, Osborn DA, Miller KV, Warren RJ, Mason GL, Hays SA, Hayes-Klug J, Seelig DM, Wild MA, Wolfe LL, Spraker TR, Miller MW, Sigurdson CJ, Telling GC, Hoover EA: Infectious prions in the saliva and blood of deer with chronic wasting disease. Science 314:133-136, 2006

16 O'Rourke KI, Baszler TV, Besser TE, Miller JM, Cutlip RC, Wells GAH, Ryder SJ, Parish SM, Hamir AN, Cockett NE, Jenny A, Knowles DP: Preclinical diagnosis of scrapie by immunohistochemistry of third eyelid lymphoid tissue. J Clin Microbiol 38:3254-3259, 2000

17 O'Rourke KI, Spraker TR, Hamburg LK, Besser TE, Brayton KA, Knowles DP: Polymorphisms in the prion precursor functional gene but not the pseudogene are associated with susceptibility to chronic wasting disease in white-tailed deer. J Gen Virol 85:1339-1346, 2004

18 Raymond GJ, Raymond LD, Meade-White KD, Hughson AG, Favara C, Gardner D, Williams ES, Miller MW, Race RE, Caughey B: Transmission and adaptation of chronic wasting disease to hamsters and transgenic mice: evidence for strains. J Virol 81:4305-4314, 2007

19 Richt JA, Kunkle RA, Alt D, Nicholson EM, Hamir AN, Czub S, Kluge J, Davis AJ, Hall SM: Identification and characterization of two bovine spongiform encephalopathy cases diagnosed in the United States. J Vet Diagn Invest 19:142-154, 2007

20 Williams ES: Chronic wasting disease. Vet Pathol 42:530-549, 2005

Request reprints from Dr. A. N. Hamir, National Animal Disease Center, ARS, USDA, 2300 Dayton Avenue, PO Box 70 Ames, IA 50010 (USA). E-mail: amir.hamir@ars.usda.gov. 